\title{
A hospital base epidemiology and pattern of acute adult poisoning across Iran: a systematic review
}

\author{
Malihe Moradi ${ }^{1}$, Kazem Ghaemi ${ }^{2}$, Omid Mehrpour ${ }^{3}$
}

${ }^{1}$ M.D. General Physician, Medical Toxicology and Drug Abuse Research Center (MTDRC), Birjand University of Medical Sciences, Birjand, Iran

${ }^{2}$ M.D. Neurosurgery specialist, Associate Professor, Department of Neurosurgery, Faculty of Medicine, Birjand University Of Medical Sciences, Birjand, Iran

${ }^{3}$ M.D , Fellowship of Medical Toxicology, Associate Professor, Atherosclerosis and Coronary Artery Research Centre, Birjand University of Medical Science, Birjand, Iran

Type of article: Systematic review

\begin{abstract}
Introduction: Poisoning is one of the most important health issues in the world. There is no exact statistic regarding the epidemiology of poisoning in Iran. The aim of this systematic review was to study the epidemiology of poisoning of adults in Iran.

Methods: All the published papers regarding the epidemiology and patterns of adult poisonings in different parts of Iran were reviewed in bibliographical databases, including SID, Iran Medex, Medlib, Magiran and Embase, Scopus, PubMed, and Google Scholar, without time limitation up to March 21, 2016. We searched for the terms poisoning, Iran, and epidemiology. After the final analysis, 38 articles that fulfilled all the required conditions were selected.

Result: In this article, we show that in most Iranian cities, except Ahvaz, pharmaceutical drugs, especially psychiatric pharmaceutical drugs, are the most common cause of poisoning in adults. In the Southwest region of Iran, poisoning due to envenomation is a very common. Although pesticide and opioid poisonings are less common, they are an important cause of death due to poisoning in Iran.

Conclusion: Pharmaceutical drugs are the most common cause of poisoning in most Iranian cities and it is recommended not to store pharmaceutical drugs at home and to set special rules regarding proper description of pharmaceutical drugs. More public health instruction is essential in the Southwest cities of Iran in order to reduce animal poisonings.
\end{abstract}

Keywords: Epidemiology, Poisoning, Iran

\section{Introduction}

\subsection{Background and study logic}

Poison involves any substance that can cause a disorder in the body through a chemical action (1). Contact with toxins has become one of the most common causes of serious medical conditions both in developed and developing countries (2). According to the World Health Organization's estimates, over 2000 people die simply because of insecticides on a yearly basis (3). Poisoning-associated death has been rapidly increasing in the United States since the 1970s (4). In developing countries, various conditions lead to higher rates of poisoning, including insufficient rules and regulations concerning pharmaceutical drugs and chemicals, poor monitoring system, and easy accessibility to a variety of pharmaceutical drugs and chemicals (5). Iran is a developing country with a population of over 70 million (6). Poisoning pattern varies across Iran (7). Poisoning is the most common cause of hospitalization and the second most common cause of death in Iran (8). A recent study showed that, from among poisoned patients admitted to a hospital in Tehran, $79 \%$ were reported as intentional poisoning with drugs (3).

\section{Corresponding author:}

Associate professor Dr.Omid Mehrpour, Medical Toxicology and Drug Abuse Research Center (MTDRC), Birjand University of Medical Sciences (BUMS), Moallem Avenue, Birjand, 9713643138 Iran.

Tel \& Fax: +98.5632381270, Email: omid.mehrpour@yahoo.com.au Received: April 02, 2016, Accepted: July 03, 2016, Published: September 2016 iThenticate screening: July 01, 2016, English editing: July 27, 2016, Quality control: August 02, 2016

(c) 2016 The Authors. This is an open access article under the terms of the Creative Commons Attribution-NonCommercialNoDerivs License, which permits use and distribution in any medium, provided the original work is properly cited, the use is non-commercial and no modifications or adaptations are made. 
However, another study performed over a 3-year timespan reported insecticides and opioids as the two leading causes of death in Northern Iran (9). The highest rates of alcohol poisoning were reported in Isfahan and Tabriz, at about $3.7 \%$ and $8 \%$, respectively $(10,11)$. Stings and bites of scorpions and certain types of snakes are also major health problems in the south and southwest of Iran (12). Carbon monoxide poisoning is common in cities, such as Tehran, that have a high density of motor vehicles and in areas with cold climates $(13,14)$. Morbidity and mortality associated with poisoning vary from one place to another and changes over time as new chemicals are used. Often, correct diagnosis and appropriate treatment are life-saving. Thus, knowledge of the overall pattern of toxicity in a particular area can help early diagnosis and management of poisoning, hence reduced morbidity and mortality (15).

\subsection{Objective of research}

In this study, the patterns and prevalence of poisoning in different parts of Iran were investigated to aid in prevention and treatment of poisoning.

\section{Material and Methods}

\subsection{Materials}

As a review article, this study reviewed all published papers on the epidemiology of hospital base acute adult poisoning in Iran. Variables, including age, gender, marital status, place of residence, education, occupation, and types of toxic substances, were studied. All databases were searched for papers published before March 21, 2016. Google Scholar, Embase, Scopus and PubMed databases were searched for international sources, and SID, Iran Medex, Medlib, Magiran were searched for Persian papers. In case the topic and the abstract were relevant, that full text was studied and keywords used in this study included "epidemiology", "poisoning", "Iran", and "toxicity".

\subsection{Selection criteria}

The search was restricted to English and Persian language articles. All articles found during the search were evaluated for competence and inclusion. After compliance with inclusion criteria, the articles that evaluate the epidemiology and pattern of acute adult poisoning across Iran were included in the current review. Irrelevant studies or original articles that evaluated the adolescent poisoning or certain toxic substances were excluded.

\subsection{Quality assessment}

For the identification and the assessment of the quality of each article, sections, including the title, abstract, introduction, methods, results, discussion, conclusion and other information, were employed together and reviewed. The documents which contained essential criteria and matched the aims of our study were included. After final analysis, 38 articles that fulfilled all the required conditions were selected.

\section{Results and discussion}

After the search was completed using the keywords and described procedures, there remained 38 articles for final analysis were all closely reviewed. As Iran holds 31 provinces with different cultural, religious, and geographical diversities, studies limited to certain regions cannot be representative of the epidemiological characteristics of the entire country. To make this study more comprehensible with regards to available geographic studies, we considered five geographical divisions for the country and examined the epidemiological characteristics of poisoning in each zone separately. Figure1 shows the five geographical divisions of Iran. They included:

- Zone 1: Tehran, Qazvin, Mazandaran, Semnan, Golestan, Alborz, and Qom

- Zone 2: Isfahan, Fars, Bushehr, Chahar Mahal and Bakhtiari, Hormozgan, and Kohkiluyeh, and Boyer Ahmad

- Zone 3: Western Azarbaijan, Eastern Azarbaijan, Ardabil, Zanjan, Gilan, and Kurdistan

- Zone 4: Kermanshah, Ilam, Lorestan, Hamadan, Markazi, and Khuzestan

- Zone 5: North Khorasan, South Khorasan, Razavi Khorasan, Kerman, Yazd, Sistan and Baluchistan.

In this study, we examined in detail the causes of toxicity in the various regions of Iran. Other epidemiologic factors of poisoning are summarized in Tables 1-3. 


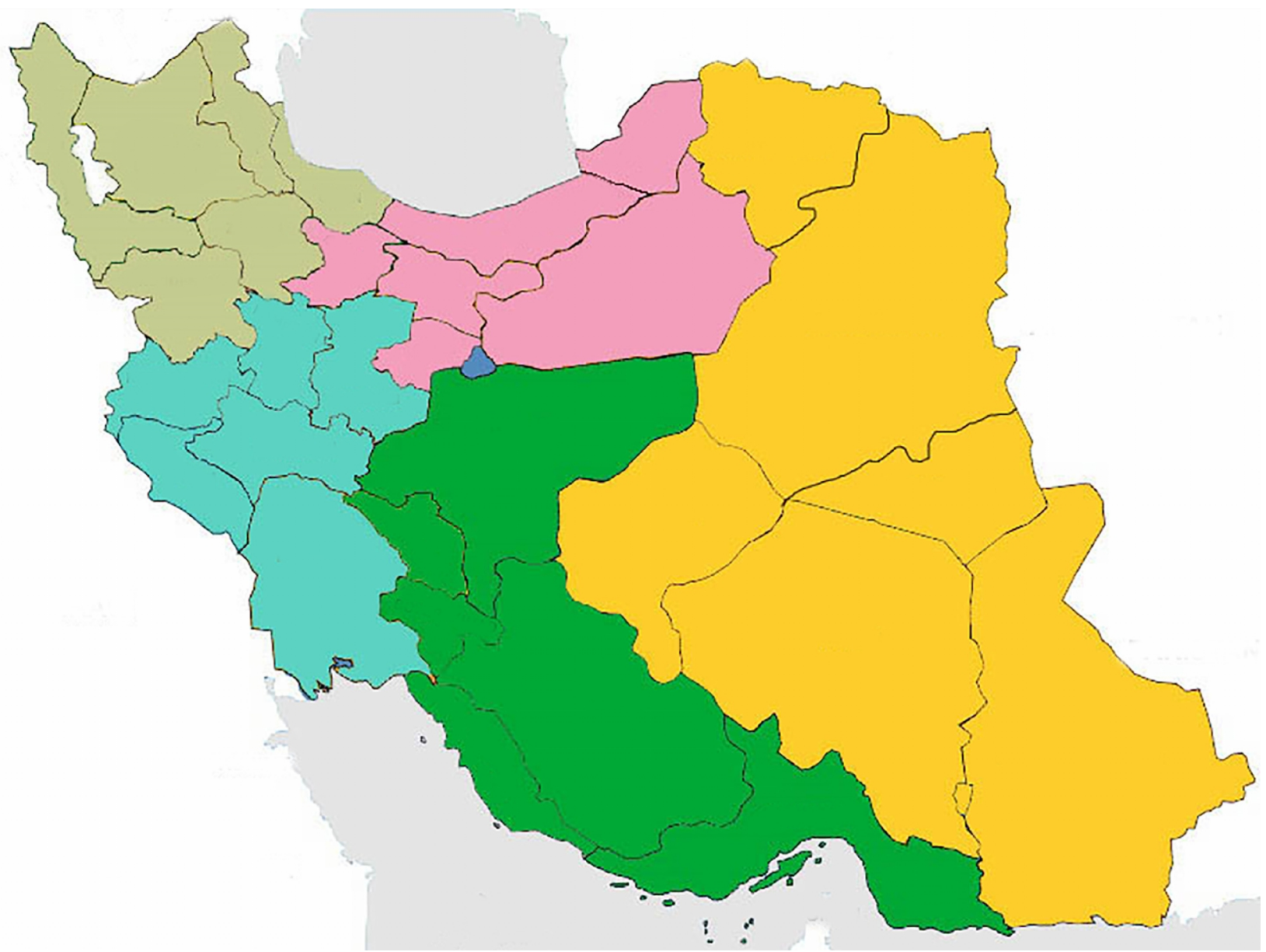

Figure 1. The five geographical divisions for Iran

Table 1. Epidemiological factors of poisoning in the $1^{\text {st }}$ geographic region of Iran

\begin{tabular}{|c|c|c|c|c|c|c|}
\hline $\begin{array}{l}\text { Ref. } \\
\text { no. }\end{array}$ & $\mathrm{n}$ & Age (year) & $\begin{array}{l}\text { Female/Male } \\
(\%)\end{array}$ & $\begin{array}{l}\text { Married } \\
(\%)\end{array}$ & Reason of poisoning (\%) & $\begin{array}{l}\text { Mortality rate } \\
(\%)\end{array}$ \\
\hline 19 & 3558 & - & $53 / 47$ & 55.8 & Intentional (57.5) & 0.97 \\
\hline 18 & 19511 & - & $62.7 / 37.3$ & - & $\begin{array}{l}\text { Intentional (93.7), } \\
\text { Accidental (4.86) }\end{array}$ & 1.3 \\
\hline 21 & 11456 & - & $49 / 51$ & - & $\begin{array}{l}\text { Intentional (25.98), } \\
\text { Accidental (74.02) }\end{array}$ & 1 \\
\hline 5 & 280 & $29 \pm 17.5$ & $24.4 / 75.4$ & - & - & 100 \\
\hline 23 & 200 & 26.82 & $51 / 49$ & $\begin{array}{l}60 \% \\
\text { single }\end{array}$ & Mostly suicide & \\
\hline 24 & 108258 & - & $47.57 / 52.43$ & - & - & 1.94 \\
\hline 25 & 172 & 29.8 & $50 / 50$ & 55.8 & All intentional & 5.8 \\
\hline 28 & 164 & $\begin{array}{l}47.47 \% \text { between } \\
12-20\end{array}$ & $58 / 42$ & 47.8 & $\begin{array}{l}\text { Suicide (47.2), } \\
\text { Accidentally (48) }\end{array}$ & - \\
\hline 6 & 2057 & $\begin{array}{l}64 \% \text { between } \\
18-29\end{array}$ & $52.9 / 44.1$ & - & $\begin{array}{l}\text { Intentional (85), } \\
\text { Accidentally (5.2) }\end{array}$ & 1.3 \\
\hline 4 & 581 & $17 \pm 22$ & $39.8 / 60.2$ & 49.2 & $\begin{array}{l}\text { Intentionally (51.6), } \\
\text { Accidental (42.7) }\end{array}$ & 22.1 \\
\hline 29 & 414 & $53.4 \%$ under 20 & $64.5 / 35.5$ & 47.8 & - & 2.9 \\
\hline 26 & 411 & $\begin{array}{l}41 \% \text { between } \\
16-25\end{array}$ & - & - & $\begin{array}{l}\text { Intentional 52.5, } \\
\text { Accidental (26.3) }\end{array}$ & 9 \\
\hline 27 & 635 & 12.28 & $58.3 / 41.7$ & 49.3 & - & 1.3 \\
\hline
\end{tabular}


Table 2. Epidemiological factors of poisoning in the $2 \mathrm{nd} \& 3^{\text {rd }}$ geographic regions of Iran

\begin{tabular}{|c|c|c|c|c|c|c|}
\hline $\begin{array}{l}\text { Ref. } \\
\text { no. }\end{array}$ & $\mathrm{n}$ & Age (year) & $\begin{array}{l}\text { Female/Male } \\
(\%)\end{array}$ & $\begin{array}{l}\text { Married } \\
(\%)\end{array}$ & Reason of poisoning (\%) & $\begin{array}{l}\text { Mortality rate } \\
(\%)\end{array}$ \\
\hline 30 & 400 & $27.57 \pm 9.20$ & $40 / 60$ & 49.2 & - & 0.75 \\
\hline 31 & 786 & - & $7.9 / 92.1$ & - & Intentional (89.5) & 0.5 \\
\hline 35 & 638 & Median: 22 & $50.8 / 49.2$ & - & $\begin{array}{l}\text { Intentional (69.3), } \\
\text { Accidental (30.7) }\end{array}$ & 1.2 \\
\hline 1 & 493 & $\begin{array}{l}75.7 \% \text { between } \\
14-29\end{array}$ & $52.1 / 47.9$ & 47.1 & Suicide (66.9) & - \\
\hline 32 & 266 & $\begin{array}{l}46.8 \% \text { between } \\
20-35\end{array}$ & $53 / 47$ & 32.8 & $\begin{array}{l}\text { Intentional (60.9), } \\
\text { Accidental (39.1) }\end{array}$ & 1.6 \\
\hline 33 & 287 & $26.3 \pm 16.9$ & $46 / 54$ & - & $\begin{array}{l}\text { Accidental (62.7), } \\
\text { Intentional (37.3) }\end{array}$ & - \\
\hline 15 & 1342 & $11-20$ & $55.7 / 44.3$ & - & $\begin{array}{l}\text { Intentional (90.2), } \\
\text { Accidental (9.8) }\end{array}$ & 2.3 \\
\hline 38 & 988 & $\begin{array}{l}44.83 \% \text { between } \\
21-30\end{array}$ & $65.1 / 34.9$ & - & Suicide (78.8) & - \\
\hline 37 & 1208 & $\begin{array}{l}63.3 \% \text { between } \\
16-25\end{array}$ & $53.6 / 46.6$ & 57.4 & $\begin{array}{l}\text { Accidental (86), } \\
\text { Intentional (14) }\end{array}$ & 4.6 \\
\hline 36 & 70 & $\begin{array}{l}38.6 \% \text { young } \\
\text { adult }\end{array}$ & $34.29 / 65.71$ & 61.43 & Intentional (62.86) & 100 \\
\hline 39 & 988 & $\begin{array}{l}37.5 \% \text { between } \\
20-30\end{array}$ & $18.4 / 81.6$ & 92.2 & - & - \\
\hline 40 & 2852 & $\begin{array}{l}51.3 \% \text { between } \\
21-30\end{array}$ & $43.2 / 56.8$ & - & $\begin{array}{l}\text { Suicide (66.53), } \\
\text { Accidental (5.01) }\end{array}$ & 2.8 \\
\hline
\end{tabular}

Table 3. Epidemiological factors of poisoning in the $4^{\text {th }} \& 5^{\text {th }}$ geographic regions of Iran

\begin{tabular}{|l|l|l|l|l|l|l|}
\hline $\begin{array}{l}\text { Ref } \\
\text { no. }\end{array}$ & $\mathrm{n}$ & Age (year) & $\begin{array}{l}\text { Female/Male } \\
(\%)\end{array}$ & $\begin{array}{l}\text { Married } \\
(\%)\end{array}$ & $\begin{array}{l}\text { Reason for } \\
\text { poisoning }\end{array}$ & $\begin{array}{l}\text { Mortality rate } \\
(\%)\end{array}$ \\
\hline 43 & 321 & $\begin{array}{l}15-20 \\
62 / 38\end{array}$ & - & - & - \\
\hline 42 & 3258 & $\begin{array}{l}34 \% \text { between } \\
18-30\end{array}$ & $49 / 51$ & - & - & 0.3 \\
\hline 41 & 840 & - & $39.8 / 60.2$ & 39.9 & $\begin{array}{l}\text { Suicide (59.6), Accidental } \\
(40.4)\end{array}$ & 11 \\
\hline 44 & 71582 & 22.3 & $54.3 / 45.7$ & - & $\begin{array}{l}\text { Intentional (54.4), } \\
\text { Accidental (45.2) }\end{array}$ & 0.6 \\
\hline 45 & 272 & $39 \pm 19$ & $37.1 / 62.9$ & - & Intentional (100) & - \\
\hline 56 & 809 & 27.7 & $50.20 / 49.8$ & 45.1 & Intentional (58) & 0.29 \\
\hline 48 & 296 & $\begin{array}{l}44.1 \% \text { between } \\
10-20\end{array}$ & $\begin{array}{l}75.4 / \\
24.6\end{array}$ & - & - & $0.3 \%$ \\
\hline 49 & 163 & $\begin{array}{l}25.3 \% \text { between } \\
0-10\end{array}$ & $47.6 / 52.4$ & $\begin{array}{l}20.8 \% \\
\text { single }\end{array}$ & $\begin{array}{l}\text { Suicide (50.6), Accidental } \\
(38.1)\end{array}$ & 4.76 \\
\hline 47 & 260 & $\begin{array}{l}56.2 \% \text { between } \\
11-30\end{array}$ & $45.4 / 54.6$ & 33.5 & $\begin{array}{l}\text { Intentional (58.1), } \\
\text { Accidental (30.4) }\end{array}$ & 1.9 \\
\hline
\end{tabular}

\subsection{Pharmaceutical drugs}

The overall increased access to pharmaceutical drugs has turned them into the most common cause of toxicity (16). Pharmaceutical drugs affecting the central nervous system are the most common drugs used in cases of selfpoisoning in developing countries. Among pain relievers, Acetaminophen is the most common poisoning drug in some areas (17). In Iran, in the first geographical zone, a study in Tehran from 2002 on 19511 poisoned cases involving pharmaceutical drugs found that benzodiazepines were the most common cause of poisoning (18). In a study on fatal poisonings in Tehran from 2002 on 341 poisoned patients, pharmaceutical drugs were the second most common cause of death after opium (19). Another study in Tehran from 2007 reported that $52 \%$ of 9,203 poisoned patients were poisoned by pharmaceutical drugs (20). In another study in Tehran from 2008 on 11,465 patients, 
hospitalization was mainly due to drug poisoning, on top of which were antidepressants, benzodiazepines, and anticonvulsants (21). In Tehran from 2009, 723 poisoning patients were studied in six major cities and $80.9 \%$ of cases were caused by pharmaceutical drugs (22). Another study in Tehran from 2012 on 200 patients, antidepressants accounted for 57\% of poisoning cases (23). A one-year study conducted in Tehran from 2012 on 280 cases of self-suicide by poisoning, 27.5\% were caused by pharmaceutical drugs (5). A study on 108,265 patients in Tehran from 2014, the most common cause of poisoning were anticonvulsant pharmaceutical drugs (24). In Karaj, from 172 cases of drug poisoning, $32.5 \%$ and $25.3 \%$ of cases were caused by benzodiazepine and tramadol, respectively (25). In two studies in Babol from 2000 and 2015, pharmaceutical drugs were the poisoning agent in $79.8 \%$ and $73.3 \%$ of cases, respectively $(26,27)$. In two studies in Sari, from 2005 and 2010, pharmaceutical drugs accounted for $77.7 \%$ and $65 \%$ of cases, respectively $(6,28)$. Another study covered Mazandaran for non-drug poisonings, from 1,546 patients, approximately $62.5 \%$ suffered from drug poisoning (4). In a study of 414 patients in Gorgan, $82.6 \%$ of the cases were poisoned by pharmaceutical drugs (29). In the second geographical zone, in two studies in Isfahan from 2015 and 2013, pharmaceutical drugs, specifically psychiatric pharmaceutical drugs, were the leading cause of poisoning $(30,31)$. Another study of 266 poisoned patients, in Shiraz, found that drug poisoning was the most common type of poisoning (68\%) (32). Another study in Fasa, on 287 poisoned patients, found that $64.5 \%$ were drug-based (33). In a study on 493 cases of poisoning in Bandar Abbas, other than suicidal or accidental cases, $26 \%$ of cases were drug abuse and $23.1 \%$ were benzodiazepines (1). In a study on 200 patients in Bandar Abbas, the most abused pharmaceutical drugs included benzodiazepines, organophosphates, acetaminophens, and tricyclic antidepressants (34). A study in Shahrekord from 638 cases of poisoning found that $89.34 \%$ had a multidrug basis (35). In the third geographical zone, in a study on fatal poisoning in Urmia, $17.15 \%$ of deaths were caused by pharmaceutical drugs, especially benzodiazepines (36). In another study in Urmia from 1,208 poisoned cases, 66.4\% were drug-based (37). In Tabriz, from 988 patients with drug and chemical poisoning, 57.4\% of cases were drug based, with many cases involving benzodiazepines and tricyclic antidepressants (14.6\%) (38). Another study in Tabriz on 1,342 patients found that $60.8 \%$ of cases involved pharmaceutical drugs (15). In a study in Ardabil on 282 patients with drug toxicity, the most widely found pharmaceutical drugs included tramadol (39\%), opium (36\%), and methadone (18\%) (39). Another study on 2,852 poisoned patients in Ardabil pharmaceutical drugs, especially tramadol, benzodiazepines, and acetaminophen were the most common causes (40). In the fourth and fifth geographical zone, in a study on 840 poisoned patients in Ahvaz, $47.5 \%$ of the cases were pharmaceutical drugs (41). In another study in Ahvaz on 3,258 cases, 56\% were caused by animal poisons followed by pharmaceutical drugs (31.6\%) (42). A study in Kermanshah on 321 poisoned patients found that $80 \%$ of the cases were drug-based (43). A study in Mashhad on 7,158 poisoned patients found that $61.4 \%$ of cases were drug based (44). In a study in Birjand on 602 patients, the most common cause of poisoning was pharmaceutical drugs (45). Another study on 809 poisoned patients in Birjand found that pharmaceutical drugs were the most common cause of poisoning (56\%) (46). In a study in Rafsanjan on 260 poisoned cases, $40.4 \%$ of cases were pharmaceutical drug injestions (47). In a study in Neyshabur on 296 poisoned patients, 83.2\% of cases involved pharmaceutical drugs (48). In one study of 163 poisoned patients in Kashan, $67.85 \%$ of the cases were caused by pharmaceutical drugs (49).

\subsection{Pesticides and insecticides}

Pesticides are chemical or biological substances used to control pests (50), including organophosphate, carbamate, and phosphide compounds (51). Application of pesticides in Iran has been increasing since 2000 (52). In a study in Tehran from 2002 on 19511 poisoned cases, 3.36\% were pesticide based (18). A study in Tehran showed that from among 346 cases of fatal poisoning, 17.3\% were caused by insecticides, which ranked third as a origin of poisoning (19). In a one-year study in Tehran on 11,465 poisoned patients, pesticides were the third most common cause of poisoning (9.37\%) and the second most common cause of death due to poisoning with a rate of $9.37 \%$ of cases $(21)$. In a one-year examination of 280 fatal poisoning cases in Tehran, organophosphate poisons were the third most common cause of death, after pharmaceutical drugs and opioids (5). In a 6-year study on 108,265 poisoning cases in Tehran, pesticides accounted for $4.72 \%$ of cases, but the most common cause of death had a rate of $24.84 \%$ (24). In a study of 581 non-drug poisoning cases in Mazandaran, the most common cause of hospitalization was pesticides (47.5\%) (4). A study on 411 cases of poisoning in Babol found that the second most common cause of poisoning, after pharmaceutical drugs, was organophosphate (29.7\%) (26). In another study on 635 poisoning patients in Babol, $26.3 \%$ of cases were due to pesticides (27). In Sari, from 2,057 poisoned patients, organophosphate insecticides and carbamates were the third most common cause of poisoning, after pharmaceutical drugs and opioids (6). In the second zone of Iran, one study of 400 poisoned patients in Isfahan reported organophosphates $(2.75 \%)$ as the third most common source of poisoning (30). In a study of 786 poisoned patients from vulnerable social stratum in Isfahan, $4.4 \%$ were due to pesticides, which was again the third most common cause of poisoning (31). In one study 
of 266 cases of poisoning in Shiraz, 8.7\% of cases were due to pesticides, rodenticides, and herbicides, which were again the 3rd most common cause (32). In one study of 493 patients in Bandar Abbas, 17.6\% were due to organophosphates and $2.8 \%$ of the cases were poisoned by rat poison (1). Another study in Shahrekord showed that, from 638 poisoned patients, $5.33 \%$ were affected by organophosphate poisons as the second most common cause of poisoning (35). For the third zone, in Urmia, $40 \%$ of 70 fatal poisoning cases were caused by pesticides, which was the main cause of death (36). Another study in this city on 1,208 cases of poisoning reported that $14 \%$ of the cases were caused by pesticides as the second most common cause of poisoning (37). In a study on 988 patients with poisoning in Tabriz, 1\% was caused by carbamates (38). A study on 840 patients in Ahvaz found that $6.9 \%$ of the cases were caused by insecticides (41). Another study on 3,258 poisoned patients in Ahvaz showed that $1.8 \%$ of patients were poisoned by organophosphates or pesticides (42). In another study on 2,852 poisoned patients in Ardabil, $15.28 \%$ were poisoned by organophosphates and aluminum phosphide, and was the most common cause of death (40). In a study in Rafsanjan on 260 poisoned cases, $13.1 \%$ of them were pesticide based (47). Finally, in a study on 723 poisoning cases in six cities, $4.5 \%$ of the cases were caused by organophosphate pesticides as the second most common cause (22).

\subsection{Opioids}

Narcotics (ab)use is rising globally and has become a health problem in developing countries, including Iran (37). Iran ranks eighth in the world in substance abuse (53). In the first geographical zone, a study in Tehran from 2002 on 19511 poisoning cases found that $11.2 \%$ of them were opium based (18). A study of 346 fatal poisoning cases in Tehran in 2001 found that the most common cause was opioids (19). In a one-year study in 2008 on 11,465 patients poisoned in Tehran, narcotics and opioids ranked third in prevalence (7.11\%); furthermore, they ranked first in terms of fatality (21). A study in Tehran on 1,208 patients with substance poisoning considered these drugs as the third most common cause of poisoning, after pharmaceutical drugs and pesticides (7.9\%) (37). A study from 2012 on 280 cases of fatal poisoning in Tehran found that $27.1 \%$ of the cases was opium-based, ranking second after pharmaceutical drugs (5). Another study from 2012 in Tehran on 200 cases, narcotics (31\%) were the second most common cause of poisoning after pharmaceutical drugs (23). In a 6-year study from 2014 in Tehran, opioids were the most common cause of poisoning, while methadone replaced it as the most common towards the end of the study. Also, opioids were the second most common cause of death after pesticides (24). In a study on 172 patients in Karaj, $38.3 \%$ of the cases were caused substance abuse, in which opium was the most common substance (18.3\%) and the most common cause of fatal poisoning (25). In one study on 411 patients with poisoning in Babol, opium was the most common cause, after organophosphates, from among all non-pharmaceutical causes of poisoning (26). In another study on 635 poisoned patients in Babol, opium was the fourth most common cause of poisoning (27). In another study on 194 patients in Sari, opium accounted for $28.3 \%$ of cases (28). In a study on 2,057 cases of poisoning in Sari, opium was the most common cause, after pharmaceutical drugs (6). In the second geographical zone, in a study in Isfahan on 400 patients with poisoning, opium was found to cause $6.25 \%$ of poisoning cases (30). Another study in the same city on 786 patients showed that $10.3 \%$ of the cases were due to substance abuse (31). In a study on 638 patients in Shahrekord, $3.14 \%$ of the cases were due to poisoning with opium, following pharmaceutical drugs and insecticides (35). In the third geographical zone, 988 patients poisoned in Tabriz were studied to find that the most common cause of poisoning was pharmaceutical drugs, with $24.5 \%$ related to opium poisoning (38). In another study in Ardabil on 2,852 poisoned patients, other than tramadol, $9.53 \%$ of the cases were due to opium. This is the most common cause of fatal poisoning after agricultural pesticides (40). In the fourth geographical zone, a study in Ahvaz on 840 patients showed that $50.4 \%$ of the cases were non-pharmaceutical poisoning cases, from which $10.9 \%$ were related to narcotic substances (41). In another study on 3,258 patients in Ahvaz, $1.6 \%$ of the cases were caused by opium poisoning (42). In a study in Kermanshah on 321 cases of poisoning, $3 \%$ were caused by illicit drugs (43). In the fifth geographical zone, a study in Birjand on 602 patients with poisoning, $7.4 \%$ of the cases were caused by illicit drugs (45). Another study on 809 patients with poisoning in Birjand reported opioids (12\%) as the second most common toxicity (46). In a study in Rafsanjan on 260 poisoned cases $23.8 \%$ and $8.1 \%$ of cases were caused by methadone and opium, respectively (47). In one study on 723 patients with poisoning in six cities, the rate of intentional poisoning cases with opium, heroin, and other intoxicating substances was $4.4 \%$, while the rate for unintentional poisoning was $41.6 \%$, which shows that the majority of the cases of poisoning with opioids are unintentional (22).

\subsection{Poisoning by Carbon Monoxide (CO)}

$\mathrm{CO}$ is a colorless, odorless, and non-stimulating gas produced as a result of incomplete burning of carbon fuels. Any contact with this gas is extremely harmful to human health (54). According to forensic reports, in 2009, there were 769 deaths by CO poisoning in Iran (13). In a study in Tehran from 2008 on 11,465 cases of poisoning, $0.71 \%$ was 
caused by CO (21). In one study of 346 fatal cases in Tehran from 2001, 2.1\% of deaths were caused by CO poisoning (19). Another study that included 108,265 patients with poisoning in Tehran from 2014, CO was the cause of $0.39 \%$ of all the cases of poisoning and $0.42 \%$ of all fatal cases (24). In a study on 2,057 cases of poisoning in Sari, 7.1\% were poisoned by CO (6). In a study in Mazandaran province, CO accounted for $0.9 \%$ of the cases (4). A study on 266 cases of poisoning in Shiraz found CO as the cause of $0.8 \%$ of all poisoning cases (32). In a study in Ardabil on 2,852 patients with poisoning, 1.75\% was due to CO (40). 7,158 cases of poisoning in Mashhad were studied to find that $17.3 \%$ of the cases resulted from CO (44). In a study on 272 cases of poisoning in Birjand, $6.9 \%$ of cases were caused by CO (45). In a study in Rafsanjan on 260 poisoned case, $1.5 \%$ of them were CO based (47). In a study on 163 patients with poisoning in Kashan, $1.8 \%$ of the cases were due to CO (49).

\subsection{Alcohol poisoning}

Mortality and morbidity of alcohol poisoning can be prevented. The prevalence of heavy alcohol use varies across the world and has been estimated as approximately $7.5 \%$ on average. While heavy alcohol use in Iran is reported as less than $1 \%$, it should be noted that, due to cultural issues, most cases remain unreported. Therefore, alcohol consumption is thought be higher than the reports claim (11). In the first geographical zone, in a study in Tehran from 2002 on 19511 poisoned cases, 4.8\% of cases were alcohol based (18). In a study in Tehran Province on poisoned people from 6 cities, alcohol abuse accounted for $10 \%$ and $2 \%$ of intentional and unintentional poisoning cases, respectively (22). In a study in Tehran on 11,465 cases of poisoning, alcohol was the cause of $3.14 \%$ of all cases (21). In a one study including 108,265 patients with poisoning in Tehran, $2.32 \%$ of all cases were caused by alcohol (24). In a one-year review of 280 cases of poisoning mortality in Tehran, $1.1 \%$ of the cases were caused by alcohol poisoning (5). In a study on 172 patients with poisoning in Karaj, 1.1\% was due to alcohol (25). In a study of non-drug poisoning in Mazandaran, a total of 581 cases were investigated to find that $13 \%$ were due to alcohol poisoning (7). In one study on 411 patients in Babol, 1\% was due to alcohol poisoning (26). In another study of 346 fatal cases in Tehran, 3\% of deaths were caused by alcohol (19). Finally, from 2,057 cases of poisoning in Sari, $2.82 \%$ had trademarks of alcohol poisoning (6). In the other geographical zones, a study on 400 cases of intentional poisoning in Isfahan showed that alcohol accounted for $1 \%$ of the cases (30). In one study on 786 patients with poisoning among the vulnerable population in Isfahan, alcohol was the cause of 3.1\% cases (45). In Shiraz, 266 cases of poisoning were studied, showing that 3.8\% were due to alcohol (32). In a study on 493 cases of poisoning in Bandar Abbas, 9.5\% of the cases were caused by alcohol (1). In a study on 638 patients in Shahrekord, $0.94 \%$ was caused by alcohol poisoning (35). In a study on 567 patients with poisoning in Tabriz, 8.4\% of the cases were caused by alcohol (38). A study on 2,852 patients with poisoning in Ardabil showed an alcohol poisoning rate of $3.22 \%$ (40). In a study on 7,158 patients with poisoning in Mashhad, alcohol was the cause of $6.1 \%$ of poisoning cases (41). In a study in Rafsanjan on 260 poisoned cases, 3.8\% of them were alcohol based (47). Finally, in a study in Kashan on 163 patients with poisoning, 3.06\% of poisoning cases were due to acid or alcohol consumption (49).

\subsection{Insect stings and animal bites}

The highest prevalence of insect stings and animal bites is in developing countries, including Iran (55). In a study in Tehran on 19,511 poisoned cases, $0.8 \%$ of them were caused by bites (18). In one study on 108,265 poisoned patients in Tehran, animal bite poisoning amounted to $0.49 \%$ of all cases, as well as $0.09 \%$ of deaths from poisoning (24). In a study in Tehran on 11,465 cases of poisoning, $0.63 \%$ of the cases were due to bites (21). In one study on 346 fatal cases in Tehran, $0.6 \%$ of the deaths were caused by animal or insect bites (19). In one study on 411 patients in Babol, 5.8\% of the cases were caused by animal bites (26). In the survey of non-drug poisoning cases in Mazandaran, from among 581 poisoned cases, 19.3\% of the cases were caused by bites (4). $0.8 \%$ of 786 poisoned patients in Isfahan were bitten by animals or insects (31). The rate for bites by insects or animals for 266 patients in Shiraz was $9.8 \%$ (32).. In Urmia, from 1,208 patients with poisoning, $0.2 \%$ of the cases were bitten by animal and insect (33). A study conducted on 840 patients in Ahvaz showed that $39.5 \%$ of the cases were caused by snake bites or scorpion stings, which was the most common cause of non-drug poisoning (39). In a study on 3,258 cases of poisoning in Ahvaz, 56.2\% of the cases were caused by insect or animal bites (40). A study in Birjand on 809 patients with poisoning showed a rate of $7.5 \%$, which was the third most common type of poisoning (43). In a study on 163 patients with poisoning in Kashan, 7.97\% of cases were caused by insect or animal bites (46).

\subsection{Food poisoning}

In one study on 108,265 patients with poisoning in Tehran, $0.22 \%$ of all cases of poisoning were due to food (24). A non-drug poisoning study in Mazandaran reported that foods are the cause of $6 \%$ of the 581 poisoning cases (4). In one study of 411 patients in Babol, $6.8 \%$ of the poisoning cases were due to food (26). In Sari, $0.72 \%$ of the total 2,057 cases of poisoning were because of food (6). In one study of 266 cases of poisoning in Shiraz, $0.8 \%$ of the 
cases were due to food poisoning (32). In Ahvaz, a study of 840 patients showed that $0.1 \%$ of poisoning cases are caused by food (41). Another study on 3,258 cases of poisoning in the same city reported a rate of $3.7 \%$ for food poisoning (42). In a study on 272 cases of poisoning in Birjand, $17.6 \%$ of cases were due to food poisoning. In addition, this was the second most common cause of poisoning after pharmaceutical drugs (45). In a study on 163 patients with poisoning in Kashan, spoiled foods accounted for $4.29 \%$ of all poisoning cases (49).

\subsection{Other causes of poisoning}

Apart from the common sources of poisoning discussed above, there are other important factors that require attention. For example, in a study in Tehran on 11,465 cases of poisoning, $0.42 \%$ of poisoning cases were caused by organic materials (21). A study on 346 fatal cases in Tehran found that $0.3 \%$ is caused by poisonous plants (19). A study in Sari on 2,057 cases of poisoning showed that $0.97 \%$ were poisoned with poisonous plants (6). In another study in Sari on 194 patients, 3\% were poisoned by chemical substances (28). In addition, in a study of 411 patients in Babol, $3 \%$ and $5 \%$ of the cases were caused by oil and occupational poisoning, respectively (26). Disinfectants were the cause of $1.25 \%$ cases of poisoning from among 638 poisoned patients in Shahrekord (35). A study on 1,208 patients with poisoning in Urmia attributed $0.3 \%$ of cases of poisoning to oil and $2.5 \%$ to alcohol and food (36). A study in Ahvaz on 3,258 cases reported 5.5\% and 1.1\% of cases resulted from chemicals and poisonous plants (42). A total of 321 patients aged 15-20 years were studied in Kermanshah, which found that $16 \%$ of the cases were caused by chemicals (43). In Ardabil, $7.36 \%$ of the cases from 2,852 patients under study were poisoned by corrosive substances (40). A study in Mashhad on 7,158 patients with poisoning indicated that $11.9 \%$ of the cases were caused by hydrocarbons and oil (44). In a study on 272 cases of poisoning in Birjand, $11.39 \%$ of the cases were due to oil and $13.2 \%$ were caused by chemicals and toxins (45).

\subsection{Further discussion}

Pharmaceutical drugs are the most common cause of poisoning in the majority of cities in Iran. In this regard, psychiatric pharmaceutical drugs have the majority share in causing poisoning. Although, in Ardabil, poisoning by tramadol was the most prevalent agent. Other studies have shown an increase of tramadol poisoning in Iran in this decade, so tramadol poisoning is currently a major concern in some cities of Iran (56-58). This finding is different to some countries. For example, in England the most common cause of drug toxicity is acetaminophen poisoning (59). In addition, pesticides poisoning occurs at a high level, especially in agriculture cities. For instance, in northern cities and in Ardabil and Urmia, poisoning by pesticides ranks second, after pharmaceutical drug poisoning. They are indeed important contributors to fatal poisoning. In a study on poisoning in developing countries, pesticides are the most common cause of self-poisoning (17). Animal and insect bites and stings are considered as uncommon causes of poisoning in the majority of geographical regions in Iran. In southwestern Iran, however, especially in Ahvaz, they are prevalent because of the climate and geographical specifications of the region. Shared borders with the drug-producing Afghanistan have significantly contributed to easy access to drugs, especially opioids. After pharmaceutical drug poisoning, substance poisoning is the second type of poisoning, especially in eastern cities of Iran and the majority of cities in Zone 1. CO poisoning, while uncommon, is a major but preventable type of poisoning in cold regions of the country. Alcohol poisoning is relatively uncommon, but is prevalent in big cities, such as Tehran, Tabriz, Shiraz, and Bandar Abbas. Alcohol poisoning in China is the most prevalent type of poisoning (60). An examination of mortality from poisoning suggests that in the first zone, except for one study, intoxicating substances and pesticides are the most common cause of fatal poisoning. In the third zone, the most common causes of death from poisoning in Ardabil and Urmia were pesticides, followed by opioids. These findings show that poisoning by opioids and pesticides, although ranking second after pharmaceutical drugs, is a significantly important cause of death. Thus, they require special attention.

\section{Conclusions}

Poisoning is one of the most important health issues in the world, but in Iran there is no exact statistic regarding the epidemiology of poisoning. Poisoning patterns vary across Iran and studies limited to certain regions cannot be representative of the epidemiological characteristics of the entire country. Pharmaceutical drugs are the most common cause of poisoning in the majority of cities in Iran. In this regard, psychiatric pharmaceutical drugs have the lion's share in causing poisoning. Recommendations include improving education to inform people of the risks of storing pharmaceutical drugs at home and enforcement of the law in the prescription of pharmaceutical drugs only as much as required. The pattern of poisoning in western areas is unique and shows the need of public health education for residents to reduce animal bites and, hence, prevent and treat poisoning. Control of substance traffic and provision of education to the youth, in particular, is also required. Unfortunately, we do not have the 
epidemiological data regarding poisoning in all cities, so these studies are recommended to complete the final picture of poisoning in Iran.

\section{Acknowledgments:}

This paper is result of the M.D thesis of Dr. Malihe Moradi. It was supported by the Grant of Birjand University of Medical Sciences. We would like to acknowledge the assistance of the Medical Toxicology and Drug Abuse Research Center (MTDRC) at the Birjand University of Medical Sciences (BUMS).

\section{Conflict of Interest:}

There is no conflict of interest to be declared.

\section{Authors' contributions:}

All authors contributed to this project and article equally. All authors read and approved the final manuscript.

\section{References:}

1) Tabibzadeh A, Yazdani R, Zare S, Golmirzaei J, Solati M, Tavousi Tehrani B. Epidemiologic study of poisonings in patients reffering to emergency ward of Shahid Mohammadi university hospital in Bandar Abbas. Hormozgan Medical Journal. 2014; 18(4): 347-57.

2) Karbakhsh M, Zandi NS. Pattern of poisoning in the elderly: An experience from Tehran. Clin Toxicol (Phila). 2008; 46(3): 211-7. doi: 10.1080/15563650701638982. PMID: 17906992.

3) Shadnia S, Esmaily H, Sasanian G, Pajoumand A, Hassanian-Moghaddam H, Abdollahi M. Pattern of acute poisoning in Tehran-Iran in 2003. Hum Exp Toxicol. 2007; 26(9): 753-6. doi: 10.1177/0960327107083017. PMID: 17984147.

4) Mohseni Saravi B, Kabirzadeh A, Asghari Z, Reza Zadeh I, Bagherian Farahabbadi E, Siamian H. Prevalence of Non-drug Poisoning in Patients Admitted to Hospitals of Mazandaran University of Medical Sciences, 2010-2011. Acta Inform Med. 2013; 21(3): 192-5. doi: 10.5455/aim.2013.21.192-195. PMID: 24167390, PMCID: PMC3804478.

5) Khodabandeh F, Emamhadi MA, Mostafazadeh B. Epidemiological Assessment of Acute Poisoning DeathOne Year Survey. International Journal of Medical Toxicology and Forensic Medicine. 2012; 2(3): 103 -9.

6) Ahmadi AH, Pakravan N, Ghazizadeh Z. Pattern of acute food, drug, and chemical poisoning in Sari City, Northern Iran. Human and Experimental Toxicology. 2010; 29(9): 731-8. doi: $10.1177 / 0960327110361501$.

7) Mehrpour O, Abdollahi M. Poison treatment centers in Iran. Hum Exp Toxicol. 2012; 31(3): 303-4. doi: $10.1177 / 0960327110392086$.

8) Mehrpour O, Zamani N, Brent J, Abdollahi M. A tale of two systems: poisoning management in Iran and the United States. Daru. 2013: 21(1): 42. doi: 10.1186/2008-2231-21-42. PMID: 23718923, PMCID: PMC3669081.

9) Sobhani AR, Tehrani H, Nikpour E, Norouzi RN. Drug and chemical poisoning in northern Iran. 2000.

10) Massoumi G, Saberi K, Eizadi-Mood N, Shamsi M, Alavi M, Morteza A. Methanol poisoning in Iran, from 2000 to 2009. Drug Chem Toxicol. 2012; 35(3): 330-3. doi: 10.3109/01480545.2011.619193. PMID: 22289573.

11) Morteza Bagi HR, Moharamzadeh T, Pouraghaei M, Barhagi AK, Shahsavari Nia K. Epidemiology of Alcohol Poisoning and Its Outcome in the North-West of Iran. Emergency. 2015; 3(1): 27-32.

12) Vazirianzadeh B, Hosseinzade M, Moravvej SA, Vazirianzadeh M, Mosavi SA. An epidemiological study on scorpion stings in Lordegan County, south-west of Iran. Archives of Razi. 2013; 68(1): 71-6.

13) Yari M, Fouladi N, Ahmadi H, Najafi F. Profile of acute carbon monoxide poisoning in the west province of iran. Journal of the College of Physicians and Surgeons Pakistan: JCPSP. 2012; 22(6): 381-4. doi: 06.2012/JCPSP.381384. PMID: 22630098.

14) Abdollahi M, Zadparvar L, Ayatollahi B, Baradaran M, Nikfar S, Hastaie P, et al. Hazard from carbon monoxide poisoning for bus drivers in Tehran, Iran. Bull Environ Contam Toxicol. 1998; 61(2): 210-5. doi: 10.1007/s001289900750. PMID: 9702358.

15) Islambulchilar M, Islambulchilar Z, Kargar-Maher MH. Acute adult poisoning cases admitted to a university hospital in Tabriz, Iran. Hum Exp Toxicol. 2009; 28(4): 185-90. doi: 10.1177/0960327108099679. PMID: 19734268.

16) Ala AR, Shams Vahdati S, Moosavi L, Sadeghi H. Studying the Relationship Between Age, Gender and Other Demographic Factors with the Type of Agent Used for Self-Poisoning at a Poisoning Referral Center in North West Iran. Acad Emerg Med. 2011; 10: 100-2. doi: 10.5152/jaem.2011.022. 
17) Eddleston M. Patterns and problems of deliberate self - poisoning in the developing world. Qjm. 2000; 93(11): 715-31. doi: 10.1093/qjmed/93.11.715. PMID: 11077028.

18) Vatandoost H, Mirakbari S. Study Of Poisoning In Adults At Poison Control Center, Loqman-E Hakeem Hospital Tehran-Iran From April 25, 2000 To April 25, 2001. Internet Journal of Pharmacology. 2002; 1(2): $35-7$.

19) Jalali N, Pajoumand A, Abdollahi M, Shadnia S. Study of mortality rate due to acute chemical and drug poisoning in Tehran, 1997-98. JBUMS. 2001; 3(1): 34-41.

20) Mohammadi N, Karbakhsh M, Pajoumand A. Epidemiologic aspects of deliberate self-poisoning in adolescents: a hospital-based study in Tehran. Tehran University Medical Journal. 2007; 65(4): 59-64.

21) Hassanian-Moghaddam H, Pajoumand A, Sarjami S. One year epidemiological study of acute adult and adolescent poisoning admitted to Loghman Hospital, Tehran. 2004-2005. IJFM. 2008; 13(4): 235-40.

22) Azin SA, Shahidzadeh Mahani A, Abadi M, Omidvari S, Montazeri A. Substances Involved in Human Poisoning a Comparison between Intentional and Accidental Poisoning Cases. irje. 2008; 4(2): 7-17.

23) Mortazavi SM, Haaji Y, Khonche A, Jamilian H. Epidemiology and Causes of Poisoning in patients referred to Loqman Hospital, Tehran, Iran during summer 2010. IJT. 2012; 6(17): 642-8.

24) Hassanian-Moghaddam H, Zamani N, Rahimi M, Shadnia S, Pajoumand A, Sarjami S. Acute Adult and Adolescent Poisoning in Tehran, Iran; the Epidemiologic Trend between 2006 and 2011. Arch Iran Med. 2014; 17(8): 534-8. doi: 014178/AIM.003. PMID: 25065275.

25) Hashemnejad M, Fatahi R. Epidemiological Study of Poisoning in Patients of Karaj Shariati Hospital in 2011 to 2012. International Journal of Medical Toxicology and Forensic Medicine. 2014; 4(1): 17-22.

26) Moghadam Nia AA, Abdollahi M. An epidemiological study of acute poisoning in Babol during 1993-95. JBUMS. 1999; 1(1): 19-26.

27) Mahdizadeh GH, Manouchehri AA, Zarghami A, Moghadamnia AA. Prevalence and Causes of Poisoning in Patients Admitted to Shahid Beheshti Hospital of Babol in 2011-2012. J Babol Univ Med Sci. 2015; 17(7): 22-8.

28) Karami M, Ebrahimzade A, Yousefi P, Khani K. Investigation of Drug Poisoning Effects in Boo-Ali and Nimeh-Shaban Hospitals During 2000 -2002. RJMS. 2004; 11(42): 629-35.

29) Abdollahi A, Nasiri H, Taghavi Kish B, Abbasi A. Epidemiology of toxicity in referees to 5 th Azar teaching-thrapeutic center of Gorgan city in 2003. Journal of Gorgan Bouyeh Faculty of Nursing \& Midwifery. 2005; 2(2): 42-6.

30) Sabzghabaee AM, Soleimani M, Farajzadegan Z, Hosseinpoor S, Mirhosseini SM, Eizadi-Mood N. Social risk factors and outcome analysis of poisoning in an Iranian referral medical center: A toxicoepidemiological approach. J Res Pharm Pract. 2013; 2(4): 151-5. doi: 10.4103/2279-042X.128144. PMID: 24991624, PMCID: PMC4076928.

31) Masoumi Gh, Ganjei Z, Teymoori E, Sabzghabaee AM, Yaraghi A, Akabri M, et al. Evaluating the Prevalence of Intentional and Unintentional Poisoning in Vulnerable Patients Admitted to a Referral Hospital. J Isfahan Med Sch. 2013; 31(252): 1452-60.

32) Aryaie M, Dokoohaki R, Rezaeian Mehrabadi A, Bakhsha F. Epidemiological Study of Poisoning in Teaching Hospitals in Shiraz in 2008. Journal of Alborz Health. 2012; 2(1): 71-6.

33) Karimi Sh, Najafi Kelyani M, Abadi R, Dari poor F .Epidemiological evaluation of types of poisoning in referees to Vali asr teaching-thrapeutic center. Iranian Congress of Addiction, Poisoning and Nursing Care 27-29 Oct. 2010.

34) Zare H, Javidan MA. Evaluation of 200 drug poisoned patients in Shahid Mohammadi hospital of Bandar Abbas from 1st Farvardin to end of Tir of 1997.1997.

35) Akhlaghi M, Arbabi Z, Khadivi R. Pattern of acute poisoning in Shahrekord (Western Iran). Asian Journal of Epidemiology. 2009; 2(1): 9-12. doi: 10.3923/aje.2009.9.12.

36) Boshehri B, Salimi S, Ranjbar S. Mortality From Acute Poisoning in Urmia: A Three-Year Retrospective Study. Iran Red Crescent Med J. 2012; 14(12): 838-9. doi: 10.5812/ircmj.1887. PMID: 23482496, PMCID: PMC3587878.

37) Shaikhi N, Zare Fazlolahi Z, Maleki M, Maleki M, Shaikhi N, Zare fazlohahi Z. Epidemiology of Adult poisoning In Talegani Hospital of Urmia 2004a-2007. Journal of Urmia Nursing And Midwifery Faculty. 2010; 8(2): 74-69.

38) Eslami M, Kousha S, Fesharaki M, Kazemi N, Ghafarzad A, Zamani M, et al. Evaluation prevalence and causes of drug and chemical poisoning in patients referred to emergency wards of Sina Hospital of Tabriz University of Medical Sciences at 2012-13. International Journal of current research and academic review. 2014; 2(7): 187-94. 
39) Farzaneh E, Mostafazade B, Shafaiee Y. Evaluation of Clinical Symptoms and Associated Factors in the Drug-Induced Toxicity in Patients Referred to Hospital: A Cross-Sectional Study. J Phys Pharm Adv. 2015; 5(1): 530-5. doi: 10.5455/jppa.20150125030925.

40) Farzaneh E, Amani F, Sadeghiyeh S, Sayad Rezaeei E, Mirzarahimi M, Mostafazadeh B, et al. Acute Poisoning in Adults Admitted in Ardabil Imam Khomeini Hospital. J Ardabil Univ Med Sci. 2012; 12(5): 95-102.

41) Kassiri H, Feiz Haddad MH, Ghasemi F, Rezaei M, Ghanavati F. An Epidemiologic and Demographic Survey of Poisoning in Southwest of Iran. Middle-East Journal of Scientific Research. 2012; 12(7). doi: 10.5829/idosi.mejsr.2012.12.7.7155.

42) Jalali A, Savari M, Dehdardargahi S, Azarpanah A. the pattern of poisoning in Southwestern Region of Iran: Envenoming as the Major Cause. Jundishapur J Nat Pharm Prod. 2012; 7(3): 100-5. PMID: 24624164, PMCID: PMC3941846.

43) Najafi F, Ahmadi Jouibar T, Moradi Nazar M, Izadi N. Causes and Risk Factors of Self- Poisoning in Adolescents 15 to 20 Years: A Single-Center Study With 321 Patients. IJFM. 2012; 18(1): 33-8.

44) Balali-Mood M. Pattern of Acute Poisonings in Mashhad, Iran 1993-2000. Journal of Toxicology: Clinical Toxicology. 2004; 42(7): 965-75. doi: 10.1081/CLT-200042550.

45) Mortazavi Moghadam SGH, Saadatjoo SA, Oliyaee SK. Epidemiology of accidental poisoning in patients referred to teaching thrapeutic center (Birjand 1999). JBUMS. 1999; 7(1): 5-8

46) Chavoshi SAK. Epidemiological characteristics of acute adult poisoning in Valiasr hospital Birjand a descriptive analytic study 2009.

47) Torkashvand F, Sheikh Fathollahi M, Shamsi S, Kamali M, Rezaeian M. Evaluating the pattern of poisoning in cases referred to the emergency department of Ali-ebn Abi Taleb hospital of Rafsanjan from October 2013 to September 2014. J Rafsanjan Univ Med Sci. 2015; 14(4): 311-24.

48) Ghodsi H, Aliayee H. Epidemiological evaluation of toxicity in referees to 22Bahman hospital. Iranian Congress of Addiction, Poisoning and Nursing Care, 27-29 Oct. 2010.

49) Dehghani R, Fathi B, Aboo-Saaidi Z, Jalalati A, Ramezani M, Nohi M. Epidemiology of Poisonings in Shahid Beheshti Hospital in Kashan, Iran. International Journal of Medical Toxicology and Forensic Medicine. 2015; 5(3): 144-50.

50) Shahsavari AA, Khodaei K, Asadian F, Ahmadi F, Zamanzadeh SM. Groundwater pesticides residue in the southwest of Iran-Shushtar plain. Environmental Earth Sciences. 2012; 65(1): 231-9. doi: 10.1007/s12665011-1086-9.

51) Dehghani R, Moosavi GA, Esalmi H, Mohammadi M, Jalali Z, Zamini N. Surveying of pesticides commonly on the markets of Iran in 2009. Journal of Environmental Protection. 2011; 2: 1113-7. doi: 10.4236/jep.2011.28129.

52) Mostafalou S, Karimi-Mohajeri S, Abdollahi M. Environmental and population studies concerning exposure to pesticides in Iran: a comprehensive review. Iran Red Crescent Med J. 2013; 15(12): e13896. doi: 10.5812/ircmj.13896. PMID: 24693394, PMCID: PMC3955509.

53) Mehrpour O. Methamphetamin abuse a new concern in Iran. Daru Journal of Pharmaceutical Sciences. 2012; 20(73). doi: 10.1186/2008-2231-20-73.

54) Nazari J, Dianat I, Stedmon A. Unintentional carbon monoxide poisoning in Northwest Iran: A 5-year study. J Forensic Leg Med. 2010; 17(7): 388-91. doi: 10.1016/j.jflm.2010.08.003. PMID: 20851359.

55) Alavi SM, Alavi L. Epidemiology of animal bites and stings in Khuzestan, Iran, 1997-2006. Journal of infection and public health. 2008; 1(1): 51-5. doi: 10.1016/j.jiph.2008.08.004. PMID: 20701846.

56) Taghaddosinejad F, Mehrpour O, Afshari R, Seghatoleslami A, Abdollahi M, Dart RC. Factors related to seizure in tramadol poisoning and its blood concentration. J Med Toxicol. 2011; 7(3): 183-8. doi: 10.1007/s13181-011-0168-0. PMID: 21735309, PMCID: PMC3550210.

57) Mehrpour O. Addiction and seizure ability of tramadol in high-risk patients. Indian J Anaesth. 2013; 57(1): 86-7. doi: 10.4103/0019-5049.108584. PMID: 23716779, PMCID: PMC3658350.

58) Khosrojerdi H, Afshari R, Mehrpour O. Should activated charcoal be given after tramadol overdose? Daru. 2013; 21(1): 46. doi: 10.1186/2008-2231-21-46.

59) DR Camidge, RJ Wood, DN Bateman. The epidemiology of self-poisoning in the UK. Blackwell Publishing Ltd Br J Clin Pharmacol. 2003; 56: 613-9. doi: 10.1046/j.1365-2125.2003.01910.x.

60) Chen F, Wen JP, Wang XP, Lin QM, Lin CJ. Epidemiology and characteristics of acute poisoning treated at an emergency center. World J Emerg Med. 2001: 1(2): 154-6. PMID: 25214960, PMCID: PMC4129745. 